\title{
Telling Stories: Enhancing Cultural Literacy in the Primary Classroom
}

\author{
Beth Howell \\ University of Durham, United Kingdom
}

\begin{abstract}
This paper draws on theory and educational policy about creativity and literacy; it includes an analysis of short stories composed orally by boys and girls aged 8-11 years. Data was collected during two small scale exploratory projects conducted in British Primary Schools, one in the North of England and one on a Hebridean island off the coast of Scotland. A consideration of literacy, which relates here to the pupils' treatment of theme, character, setting and structure, will help to develop an understanding of their ability to access the imagination, express original ideas and compose a coherent, whole text. This discussion will explore how story telling may enhance children's sense of identity and cultural literacy; it also points to some routes for practical implementation of creative teaching and learning.
\end{abstract}

Key Words: Creativity, Literacy, Imagination, Culture, Citizenship.

\section{Introduction}

Teaching children the art of story telling is important. Being able to tell a story helps to establish a sense of identity, develop human relationships and understand our place in the world. Story telling is self-affirming. It is an empowering, sometimes subversive, political act [1]. It is also a hopeful activity. Learning the art of story telling is part of growing up; it enhances social and cultural understanding [2]. Perhaps, most importantly, giving children the opportunity to engage with stories and to become story tellers themselves is a joyful project.

Until children learn to play with language, they cannot understand its systems of meaning. As the Primary curriculums in England [3] and Scotland [4] focus more on creativity, teachers can begin to address their concerns about the suppression of the imagination and marginalization of creative activity due to previous impositions such as the National Literacy Strategy (NLS). As a result of the NLS, which affected schools in England from the turn of the century, teachers have been concerned that the fragmentation of texts and compartmentalization of
'English' has affected pupils' sustained engagement with and enjoyment of reading and writing. Therefore, one purpose of this study was to evaluate children's ability to develop a sense of structure in a 'whole' text. Emerging patterns which might suggest gender differences in the Primary stage were also explored as in a previous story telling project with older pupils [5].

\section{Research Background}

\subsection{Creativity}

It is important that children have time and space to reflect upon their experiences and to express themselves creatively. Creativity involves the process of drawing on foundational knowledge and understanding, problem solving, reflection, making connections and making something new and valuable from those connections [6, 7]. It is also necessary to equip children with the knowledge, skills and understanding they need in order to produce good work [8]. Whilst the terms 'engagement', 'enjoyment' and 'empowerment' are welcome within the new discourse of the National Curriculum in England, what these words mean and how they can be demonstrated and measured is not clear. A central objective seems to be that teachers develop their excellence in response to the "workforce remodeling agenda" of the former Labour Government. Thus, the invitation to enable and allow children to take risks, enjoy freedom and experience empowerment is being juxtaposed by terminology which is still very much about testing, targets, measurement, accountability and performance management [9].

Encouraging pupils to exercise their imaginations must become a central 'pedagogic concern' rather than testing 'discrete skills' which have been disengaged, disconnected and reduced to a 'naming of parts'. If we are to create spaces wherein children can develop their imaginative work, teachers need structured tasks and a 'precise pedagogy' which also addresses how we conceptualize terms such as 'imagination' [10]. A recovery and safe-guarding of imaginative practice through teaching and learning is a necessary process if we are to enable pupils and teachers to become resourceful and effective 
thinkers. Teaching and learning can be both creative and part of an engaging programme which prepares children for life and work by developing cultural and linguistic capital along with a joyful appreciation of language. Creative composition allows pupils to create transcendent selves, to imagine how to resolve problems and conflict, to inhabit other selves and exercise empathy. These imaginative processes support life-long learning and well being. Creativity, therefore, is an important part of being human.

\subsection{Cultural Literacy}

Another area of consideration is whether and to what extent the increase of media in the form of television, video and computer games in the home impacts on children's ability to actively draw on their imaginations and produce engaging and original work [11, 12]. A pertinent area for exploration is the extent to which children's cultural influences have a good or bad effect on their compositions. Children derive an understanding of story from many sources and it could be argued that some derivations are advantageous. A problem may arise if there is an over-dependence on these sources which is damaging to the imagination and results in a lack of thoughtfulness, direct repetition and cliché.

Both pupils and teachers can learn from a critical approach to children's cultural literacy and preferences. Pupils can be encouraged to question and reflect upon their choices and teachers can gain insights into children's "narrative pleasures" in order to help them develop their writing skills [12]. Whilst children's popular culture may be replicated within their stories, teacher intervention in the form of questioning and peer review, leading to collaborative editing, can allow those copied themes and conventions to be explored, and, if necessary, reevaluated. Thus, we may address the concern that children's work becomes derivative or merely reflective of their cultural influences.

Literacy is shaped as a social practice and is linked to larger social structures; it should not be understood as a demonstration of skills but as an emerging act of consciousness and resistance [13]. What people do with technologies of writing and inscription is shaped in relation to the contexts of work, of consumption and leisure, of citizenship and national ideology, and of varied projects of 'selfhood' and cultural identity. Creative 'performance' is situated and contextualized. The act of composition, therefore, can be understood as "a specific form of social practice embedded in our social system and impregnated with its own social history” [14]. Whereas language is contextual and reflective of social forces, literary text can transcend and subvert, consciously disrupt authority and thus become a liberating force. Educators can pursue links between literacy and social formation through a broader understanding of literacy not just as "social practice”, but also as curriculum practice [15].

\subsection{Storytelling}

This paper explores how story telling may be employed as an effective medium through which we can enable pupils to develop transcendent, socially aware and reflective selves. Story telling provides opportunities for children to explore language, experiment and engage with it, and thus become creatively and critically literate. Enculturation and empathetic response are essential if we are to take an active role within our particular contexts. Also, as global citizens, an understanding of what it means to be able to tell a story is an enlightening, transformative and emancipatory experience which facilitates the development of both agency and connectedness. Storytelling can be validated as a credible and socially inclusive method of collecting reliable data which identifies and reveals children's discourses and demonstrates how they position themselves and others [16, 17]. When children become authors of their own narratives, we gain an insight through fiction to their world view.

\subsection{Oral story telling}

For the purposes of this research project oral story telling was employed as a medium through which children's creative and cultural literacy can be explored. This article, therefore, is an examination and evaluation of Primary school pupils' stories and may consequently inform practice in the classroom. The participants were encouraged to plan and revise their work, thus reflection and critical literacy was also part of the project. The advantages of talk for textual development have long been acknowledged $[18,19]$. Recent research which examined the benefits of 'oral rehearsal' for composition and reflection found that there was an increase in confidence, enthusiasm and performance for younger pupils. Despite theory and policy directives, however, this study also found that teachers did not fully understand what 'oral rehearsal' was and how it could be implemented in the classroom [20].

\section{Research Objectives and Theoretical Foundations}

Narrative theory can be adapted in order to enable pupils to understand the codes and organizing principles of plot and consequently to compose their own stories. The objective here was to consider how we might equip pupils with the knowledge, understanding and skills needed to create well structured narratives which take account of place, person and the reader through planning, composition 
and reflection. The study was informed by an eclectic consideration of narratology drawing on the work of both structuralist and post-structuralist theorists. Attention was paid in particular here to Propp [21] and Bahktin [22]. Propp's simplified structuralist model, drawn from a wide range of stories such as fairy tales, myths, legends and epics, describes highly specific and defined roles. His definitions of functions and 'spheres of action' within plot are useful for identifying the recurring themes and types of characters which are presented in children's stories [21]. Bahktinian theory offers a post-structuralist view wherein a dynamic system of meaning-making is formed through the relationship between author, narrator and reader [22].

In order to explore pupil voice and competency we need to consider their choices. Working out the effect of writers' choices enables a reader to create meaning. An analysis which focuses on how a text is written can lead to an understanding of what it says. The proposition here is that ideally a story will consist of the following: Conflict (exists outside the parameters of the story); Crisis (a problem which is encountered or an event which brings Conflict into the story); Climax (a turning point) which leads to Resolution. Of particular interest is the extent to which pupils demonstrate an ability to employ Crisis and Resolution, the structural narrative elements through which a character must negotiate a pathway.

\subsection{Research Questions}

This exploratory study aimed to address the following key areas: When children are invited to tell a story, what do their stories consist of in terms of theme and how are they structured as regards development of plot and character? Therefore, in addition to an exploration of pupils' interests and world view, another main focus of this evaluation is a consideration of the extent to which pupils are able to express their imagination within a coherent and satisfying whole narrative structure. The following questions then were considered during the process of analysis:

- To what extent do pupils' narrative compositions offer an insight into their 'world view'?

- To what extent are pupils able to develop transcendent, socially aware and reflective selves through oral story telling?

- To what extent are pupils able to organize their ideas coherently and employ a range of structural elements in their stories?

- How do pupils present problem solving through character development?

- To what extent do pupils create stories which are original?

- Are there any notable gender differences?

\section{Method - Data Collection}

In school A (North of England) 24 pupils took part aged 8 - 9 years; 12 girls and 12 boys were randomly selected from three junior classes. In School B (Hebrides, Scotland) 10 children took part, 7 girls and 3 boys (the entire junior class) aged between 8 and 11 years. The work was carried out on a one to one basis with the participants in order to gain an individualistic insight rather than one which may be influenced by immediate classroom relationships and peer pressure. Brief oral interviews were conducted with the pupils prior to, during and after the composition exercise to establish how the pupils were structuring their ideas. The intention was to explore the pupils' development of plot, sense of place and person and to consider the planning, drafting and editing processes employed.

In each case the researcher acted as scribe writing down exactly what the participants said. The introduction of the 'scribe' element facilitates an investigation of literacy as it relates to oral composition rather than transcription which consists of technical accuracy such as grammar, spelling and handwriting. Whilst current external assessments (such as SATS) are often focused on these latter surface attainments at Key Stage 2, the aim here was to investigate the pupils' engagement with thematic content, setting, character, and their ability to organise ideas as well as express their imaginations in an immediate and observable way. There was some minimal intervention as regards paragraphing (new place, new person, new action), sentencing (use of commas and full-stops to reduce the use of 'and', 'then'), and intermittent prompts to use names in order to reduce sentences beginning with 'he / she'.

In both schools each pupil chose one object from a collection arranged on the desk. Some of the objects were natural, for example, a piece of bark, a shell, a stone from the beach, a feather. There were other objects which were non gender specific but imaginatively evocative such as a small wooden box with silver moons and stars on it, a bandage, an old door knob. After they had chosen their object, the pupils were given a planning sheet which consisted of a number of circles in which they could write. The pupils were asked to make brief notes about the setting for their story (time and place), add a few words to describe their object and include some words to introduce at least one character. They were also encouraged to outline a very simple structure in terms of action regarding what happens at the beginning, middle and end of their story. Children whose writing skills were undeveloped communicated their ideas orally at this stage.

After the short planning process the children were invited to begin telling their stories which were simultaneously written onto a laptop; in this way the pupils were able to see their texts develop on the 
screen as they composed them orally. When their compositions were finished the stories were read again and any changes discussed. The pupils usually spent another five to ten minutes editing and producing their finished version. In each case the process took between 20 to 30 minutes.

\section{Outcomes and Evaluation}

The discussion below offers an indication of areas of interest revealed by the findings. The analysis of data collected from both schools focuses on content / theme, complexity of style and structure and explores evidence of any developed sense of person. Propp's list of folktale archetypes (or 'actants' within his 'dramatis personae') offers a useful way into reading, writing and analyzing stories [21]. It is interesting to see the extent to which these figures, themes and their consequent functions appear in the pupils' stories. The hero, the villain, the helper, leaving and returning home, losing and finding objects, the gift and use of magic objects, transportation and pursuit; recognizable characters, themes and plot lines emerged in the stories from both cohorts. This seems to indicate that the pupils were able to draw on their experiences of narrative (text or film) and assimilate these features and elements within their own compositions.

From these small samples some similarities and differences between the boys' and the girls' compositions regarding theme, character, setting and structural devices have been identified. These correlate to a certain extent to findings from a previous pilot project and may inform future pedagogical intervention, as suggested elsewhere, in order to encourage boys' sustained engagement with whole text [5].

\subsection{Theme}

The object element resulted in many stories having a supernatural theme. The word "magic" appeared in five of the boys' titles and four of the girls'. In general both boys and girls invested their objects with some sort of power. Good luck and bad luck were equally popular themes among both boys and girls. There were nine adventures across space and time. Four of the boys wrote about transportation; five of the girls were taken to another world, place or time through the power of their object. The theme of lost and found was also popular, three boys and four girls included this element. Two boys composed stories about ghosts. More boys wrote about danger and scary creatures; more girls wrote about family and friends. Most of the stories were original with only two boys and one girl drawing on Arthurian legend. One boy and one girl included glimpses of plot lines which were recognizable from film but these elements did not dominate their stories.

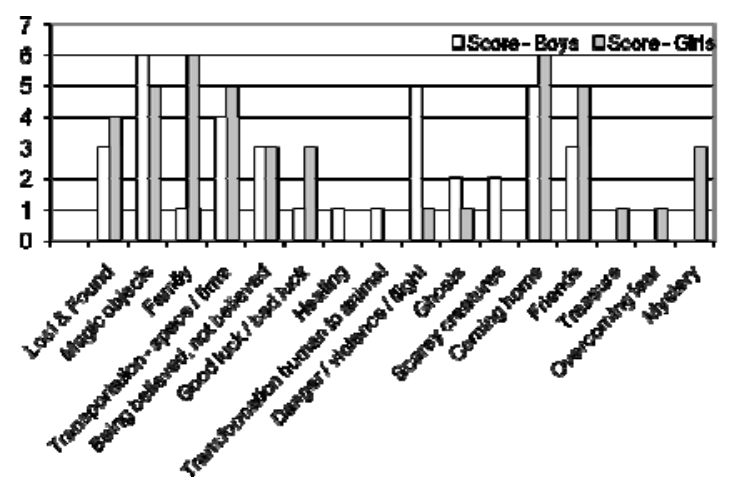

Figure 1. Themes

\subsection{Structure}

Overall, the girls' stories were longer and more complex in terms of plot; the average length for the girls' stories was 473 words compared with 322 for the boys. The longest story by a girl was 926 words; the longest story by a boy was 611 . Most boys and girls managed to structure their stories within a simple beginning, middle and end framework. One clear difference is that, whilst both boys and girls introduce problems in their stories, more girls were concerned to create and work out resolutions, or cliff-hangers which suggested possible sequels. Conversely, many of the boys were satisfied with offering very brief endings which did not attempt to tie up loose ends.

The girls were, overall, more meticulous editors, in some cases spending up to fifteen minutes revising their texts.

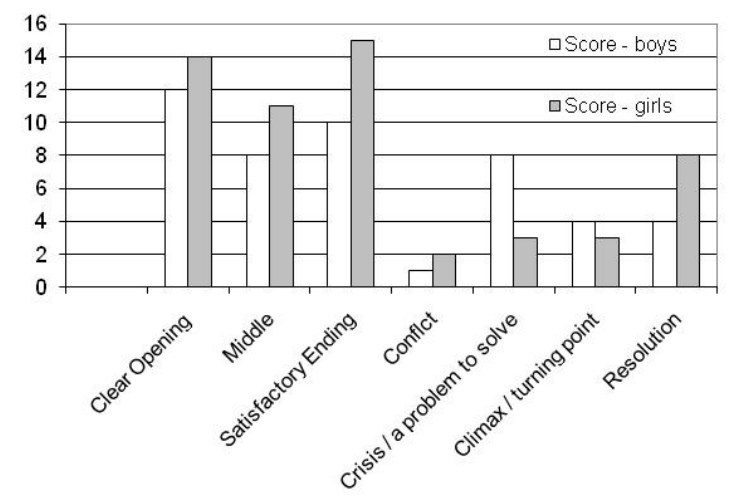

Figure 2. Structural narrative devices

\subsection{Character and setting}

The most notable difference between the boys' and girls' compositions was the development of character (a clear sense of person) and the ability to 
create a sense of place by offering a detailed description of setting. In both instances girls outperform boys.

As expected, most girls wrote about young female characters and most boys wrote about young male characters. Only one of the boys introduced a female character, a grandmother, whereas nine of the girls wrote about a range of male characters including a magician, a clown, a king, an explorer. Four of the male figures were brothers to the female protagonists. In these stories one of the common themes was a co-operative struggle to overcome difficulties. Two of the boys' stories included other male friends but the majority centered around one male character, always the age of the author and often an active, solitary hero.

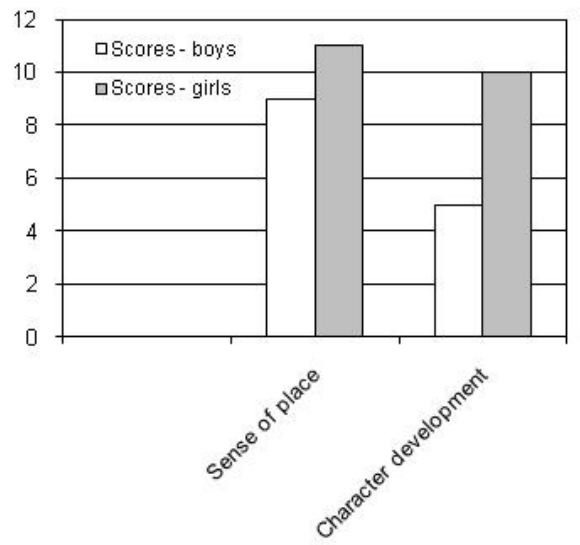

Figure 3. Person and place

\section{Some detailed analysis}

Only three pupils from these cohorts managed to move beyond narrative structure at its simplest level (beginning, middle and end) and compose stories which demonstrated a more sophisticated understanding of narratorial elements such as Conflict (which exists outside of the plot), Crisis (which brings the conflict into the narrative framework), Climax (a turning point) and Resolution.

\section{1. "Rosie and the Wizard"}

The story discussed below was composed by a girl (aged 8). This is the opening to her story:

"One Autumn evening, a family was out walking when suddenly Rosie, a ten year old girl, saw an interesting looking cave ahead. She ran off to investigate a bit more but her family didn't notice and they carried on walking. Rosie called them over to look at the cave she had found but then she realized that they had disappeared off into the distance and they could not hear her calling. Rosie felt absolutely devastated. They were much too far away now and she had no hope of catching them up.
Rosie felt a shiver down her spine. It was starting to get dark and very cold. She was just about to go into the cave for some shelter when she stood on something hard. She brushed away the crispy Autumn leaves and underneath was a small, old, copper-plated wooden chest. Rosie tried to open it but she couldn't and only the catch lifted up. She wondered what the purpose could be of a box that didn't open."

This is an example of a good beginning for several reasons. Firstly, the narrative has a clear sense of time and place. Secondly, the reader is aware of the character's position and feelings. Thirdly, an element of intrigue begins to move the plot forward and further engages the reader. This suspense raises questions in the reader's mind and creates further empathy or understanding of the character's situation and thus a shared point of view begins to emerge. There is the promise of development, things need to be resolved. The lost and found theme is established and our heroine as both seeker and person needing to be rescued is of interest.

"Just as she was about to climb the staircase she saw that the entrance was widening again and someone was coming down. Rosie rushed to find cover but, in her blind panic, she couldn't find anywhere. Soon she could hear the swishing of the mystery person's cloak. Rosie darted under the table just as a dark, purple shape appeared at the foot of the stairs. Rosie couldn't see a face but she could see a long, pointy, white beard.

The wizard spoke in a solemnly, deep voice,

'I know somebody is in here, I'm not going to harm you so why don't you come out?'

Rosie shuffled uneasily under the table, not sure whether to reveal herself or stay hidden. The wizard glided passed her and went to look somewhere else. Rosie took her chance and scrambled out. She headed for the stairs but just as she reached the first step the wizard turned round and saw her.

'Please stay,' he said.

His voice was exceptionally soothing and Rosie felt a warm glow of relief. He seemed to be pleading with her as if he was lonely."

Rosie's adventure continues to engage the reader. This author is able to show ("shuffled uneasily") how the main protagonist feels as well as tell ("blind panic"). The introduction of another rounded character is well conceived and the use of dialogue is effective. The issue of loneliness (conflict) emerges and is one which will need to be addressed further. The question remains as to how Rosie is going to get home (crisis).

During the narrative a friendship is formed and Rosie finds herself safe back at home with her parents after a deep sleep. This story demonstrated the popular theme of not being believed. Nevertheless, the story ends on an interesting note: 
"When she went back into her room, Rosie found a small note on her pillow. It was from the wizard and it said,

'Please come and visit me whenever you can.'

Rosie knew she should keep this to herself.”

This resolution satisfies the reader by providing closure, reassurance that a problem has been dealt with, and a sense of a future life beyond the parameters of the narrative. Rosie will visit the wizard and have further adventures knowing she can get home safely. The wizard will not be lonely anymore.

\section{2. "Overcoming Fears"}

The following story was told by a girl (aged 9). It includes relatively complex character development which is linked to dealing with an ongoing problem of bullying at school. The main protagonists of this story are twins, a boy and a girl. This is a long and adventurous story (926 words) with many twists and turns. A developed sense of place and person is evident and the action is set within a clear narrative structure as regards conflict, crisis, climax and resolution. The story opens with the following context: the twins are grounded because they stayed out too late, father has not returned after searching for them, so they go into the attic because they are bored. They can't resist opening a magical chest with stars and moons on the lid:

"When they open the chest, they grow cold and see a silver, sparkling mist all around them ... a kind voice comes out saying, 'I am spirit and will help you overcome your fears.' They find themselves saying that they had a dream about their spirit and knew that they would overcome their fear by going through an adventure.

The spirit says that their dream is true and asks them if they would like to go on an adventure. They agree to this at once because Daphne does not want to be called a wuss [slang for weakling] any longer at school and John does not want to be called a wuss at school as well. They had been bullied because last year they had been to a birthday party at a theme park and the birthday boy's mum had wanted them all to go on a spooky ride. After the ride, all the guests found out that Daphne and John did not go on the ride because they were too scared."

The children therefore revisit the source of their problem through the structural devices of conflict (bullying) and crisis (a mystical encounter with a 'helper'). The adventure continues and the children are transported through place and time. They get into a boat, travel through a passage way and emerge from a cave "when their eyes clear they find themselves in the same sort of spooky ride which was at the theme park." The spirit guide gives the children tools and advice:

"As soon as they see that the monsters are real, a sword appears in both of the children's hands. The spirit tells them to use the swords not as weapons but as tools to overcome their fear. The swords give them encouragement to overcome their fear so they go on through the tunnel fighting their way to the end until they find a fearsome monster blocking the exit. The spirit tells them that this monster is the most fierce ever to be known in the universe [...] The spirit says that that they must defeat it to overcome their fear.”

The children learn that the way to defeat their fears is to believe their spirit will help. The climax pivots on the helper's gifts of encouragement and faith:

"After a few minutes of believing, the monsters disappear and they find themselves in a land so peaceful that they can go to sleep. When they wake up they find five ladies dressed in gold bringing them food and drink. Then, the spirit comes forward and congratulates them for overcoming their fear. They ask when they can go home, as soon as they finish that question they find themselves in the attic with their father beside them. When they look at the clock, it is still 11-30am and their Dad tells them that he had only been at Grandma's because he had been too tired to come home after searching for them.”

At the end of the story the children are no longer grounded so they go to the theme park knowing that "their friends will see that they are not scared anymore."

This story offers a two-fold resolution; within the original framework of the plot their father returns but, more importantly, beyond the plot, the outcome of their adventure means that the children are no longer afraid and therefore will not be bullied. The well structured, emancipatory movement from victim to victor creates an effective sense of character development and addresses an important and problematic issue for school children. Daphne and John will be able to stand up to bullies because they have survived a scary experience. In both of the stories above the reader has invested in the character development presented due to coherent structure and a convincing sense of place and person.

\section{3. "Gavin the Troll"}

Perhaps the most satisfying story in terms of structural development and resolution was told by a boy (aged 9). In this precise and economical tale (376 words) the main character is described in the first paragraph as having "a nice personality". He is transported by means of a rusty old doorknob to "a magic land". The protagonist, who "never, ever fights" because he is "a nice little troll”, is "puzzled" and "confused" when he discovers that the creatures in the magic land are at war. He makes an excellent suggestion:

“'Why can’t all of you just share the land?' The magical creatures stopped and thought. 
'So, what are we going to do instead of fighting, then?' Grant says, 'How about a party?'

'Yeah a party!' Shout all the magical creatures waving their weapons in the air."

The narrator's reward for solving the conflict is that he gets home safely; hence we have another double resolution. Here is a glimpse of that hopeful endeavour which fiction allows. The freedom of creative engagement with story empowers the author in his imaginative state to question, revolt and resist, to imagine peace and reach a joyful resolution. From the mouth of a nine year old boy a character is created who can take control of his circumstances and help to readjust a world spoiled by war. Moving beyond the localized social context of the real and present dangers of bullying in the school playground, the narrative here touches on a more transcendent and enlightened notion of what it may mean to be a global citizen. In this boy's utopian vision moral decisions are made and heroes returned to their homes in time for bed.

\section{Conclusion}

Problem solving is an essential life skill which can be explored and learnt through story telling. Conflict, Crisis and Resolution are structural narrative elements through which a character must negotiate a pathway. Imagining how a character might solve a problem in a story is a useful and valuable skill for all children and one which can be introduced in a creative and engaging curriculum. As regards planning and editing, helping pupils to evaluate what is not worthwhile by enabling them to develop their criticality is also part of the creative process. If children are critically aware of what is valuable and what is not valuable, they will be able to express themselves more effectively. This kind of intervention can increase pupils' confidence, help them to establish a sense of their place in the world and enhance their well being.

Involving teaching support assistants and literacy co-ordinators in effective practice in the classroom would allow a replication of close, one-to-one work with pupils. We may find that the issues described above are not merely 'British' and discover similar phenomena in other countries. Emerging trends could lead to a more wide spread evaluation of the impact of similar interventions and an assessment of how their implementation may affect the confidence and skills of both teachers and pupils. This might include an exploration of which interventions or combinations of interventions school staff, parents and children perceive to be most successful and what challenges may arise which need to be addressed further.

Cultural literacy, developed through narrative composition, may foster life-long learning. We need to establish long term projects where teachers, pupils and researchers work closely together with shared purposes. In this way we can explore meaningmaking processes and develop teaching and learning in creative, cultural and critical literacy. Equipping pupils with the necessary skills to become story tellers will both emancipate and empower them to transcend the influence of media and popular culture so that they are not merely passive recipients of cultural goods but active and autonomous producers of them.

\section{References}

[1] Benjamin, Walter, Illuminations, (trans Harry Zorn), Pimlico, London, 1999, 1st ed Schriften - 1955.

[2] Zipes, Jack, Creative Storytelling: Building Community, Changing Lives, Routledge, New York \& London, 1995.

[3] Ofsted Creative partnerships: initiative and impact (Ref no. HMI 2517), Ofsted, London, 2006. www.ofsted.gov.uk.

[4] SEED (Scottish Executive Education Department), Promoting creativity in education: overview of key national policy developments across the UK, 2006. http://www.hmie.gov.uk/documents/publications/hmiepcie. html.

[5] Howell, B., "Literacy, subjectivity and the gender divide: 'the freedom of writing implies the freedom of the citizen' (Sartre, 1948)," Gender and Education 20 (5), 2008a, pp. 511-525.

[6] Howell, B., "Some Student Teachers' Conceptions of Creativity in Secondary School English," English Language Teaching 1 (2), 2008b, pp. 36-48.

[7] Newton, D.P., "Teaching for Understanding." Evaluation and Research in Education, 15 (3), 2001, pp. 119-127.

[8] Craft, A., Creativity and Early Years Education, Continuum, London, 2002.

[9] Hall, Christine \& Pat Thomson, "Creative tensions? Creativity and basic skills in recent educational policy", English in Education: Creativity and Change, 39 (3), 2005, pp. 5-18

[10] Dart, Lisa, "Literacy and the lost world of the imagination”, Educational Research, 43 (1), 2001, pp. 6377.

[11] Marsh, Jackie \& Elaine Millard, Literacy and Popular Culture: Using Children's Culture in the Classroom, Paul Chapman Publishing Ltd., London, 2000.

[12] Millard, Elaine, “To enter the castle of fear: engendering children's story writing from home to school at KS2", Gender and Education, 17, (1), 2005, pp. 57-73. 
[13] Giroux, H., "Literacy and the politics of difference" in C. Lankshear \& P. McLaren (Eds.), Critical Literacy: Politics, Praxis, and the Postmodern, pp. 367-377, State University of New York Press, Albany, NY, 1993.

[14] Rosen in Kimberley, K \& M. Meek, J. Miller (Eds.), New Readings: Contributions to an Understanding of Literacy, p. 125, A \& C Black (Publishers) Limited, London, 1992.

[15] Luke, A. and V. Carrington, "Globalisation, Literacy, Curriculum Practice” in R. Fisher, M. Lewis \& G. Brooks, (Eds.), Language and Literacy in Action, Routledge/Falmer, London, 2002.

[16] Bomer, Randy \& Tasha Laman, "Positioning in a Primary Writing Workshop: Joint Action in the Discursive Production of Writing Subjects", Research in the Teaching of English, 38 (4), 2004), pp. 420-466.

[17] Davis, Pauline, "Storytelling as a democratic approach to data collection: interviewing children about reading”, Educational Research, 49 (2), 2007, pp. 169184.

[18] Vygotsky, L.S., Mind in Society, Cambridge, MA: Harvard University Press, Cambridge, 1987.

[19] Norman, Kate (Ed.), Thinking Voices: The Work of the National Oracy Project, Hodder and Stoughton, London \& Sydney, 1992.

[20] Myhill, Debra and Susan Jones, "How Talk becomes Text: Investigating the Concept of Oral Rehearsal in Early Years' Classrooms”, British Journal of Educational Studies, 57 (3), 2009, pp. 265-284.

[21] Propp, Vladimir, Morphology of the Folktale, (Trans. Laurence Scott), University of Texas Press, Austin, 1968.

[22] Bakhtin, Mikhail, The Dialogic Imagination: Four Essays, (Trans. Emerson \& Holquist), University of Texas Press, Austin, 1981. 